\title{
Melanocortin Receptor Agonists Facilitate Oxytocin-Dependent Partner Preference Formation in the Prairie Vole
}

\author{
Meera E Modi ${ }^{*, 1,2}$, Kiyoshi Inoue', Catherine E Barrett', Kara A Kittelberger', Daniel G Smith ${ }^{2,3}$, \\ Rainer Landgraf ${ }^{4}$ and Larry J Young' \\ 'Center Translational Social Neuroscience, Silvio O Conte Center for Oxytocin and Social Cognition, Department of Psychiatry and Behavioral \\ Sciences, Yerkes National Primate Research Center, Emory University, Atlanta, GA, USA; ${ }^{2}$ Neuroscience Research Unit, Pfizer Worldwide Research \\ and Development, Cambridge, MA, USA; ${ }^{3}$ Autism Speaks, Boston, MA, USA; ${ }^{4}$ Max Plank Institute of Psychiatry, Munich, Germany
}

\begin{abstract}
The central melanocortin (MC) system has been widely studied for its effects on food intake and sexual behavior. However, the MC system, and more specifically the MC4 receptor (MC4R), also interacts with neurochemical systems that regulate socioemotional behaviors, including oxytocin (OT) and dopamine. In monogamous prairie voles, OT and dopamine interact to promote partner preference formation, a laboratory measure of an enduring social bond between mates. Here we investigated the effects of $\mathrm{MC}$ receptor activation on partner preference formation in prairie voles, as well as the interaction between the MC and OT systems during this process. Peripheral administration of the brain penetrant MC3/4R receptor peptide agonist, Melanotan II (MTII), and the highly selective, smallmolecule MC4R agonist, Pf-446687, enhanced partner preference formation in the prairie vole, but not in the non-monogamous meadow vole. MTII-induced partner preferences were enduring, as they were present I week after drug manipulation. The prosocial effects of MCR agonists may be mediated, in part, through modulation of OT, as coadministration of an OT receptor antagonist prevented MTII-induced partner preferences. MTII also selectively activated hypothalamic OT neurons and potentiated central OT release. As OT has been shown to enhance some aspects of social cognition in humans, our data suggest that the MC4R may be a viable therapeutic target for enhancing social function in psychiatric disorders, including autism spectrum disorders and schizophrenia, potentially through activation of the OT system.

Neuropsychopharmacology (20I5) 40, I856-|865; doi:I0.I038/npp.20I5.35; published online 4 March 20I5
\end{abstract}

\section{INTRODUCTION}

The melanocortin (MC) system has been studied extensively for its regulation of food intake and metabolism (Seeley et al, 2004), stress and anxiety ( $\mathrm{Lu}$ et al, 2003; Papadimitriou and Priftis, 2009), and sexual behavior (Argiolas et al, 2000; Hadley, 2005). However, few studies have explored the role of the MC system in social cognition and behavior (Kokare et al, 2010; Shimazaki and Chaki, 2005). Melanocortin 4 receptors (MC4Rs) interact with several neurochemical systems that modulate socioemotional behaviors, including oxytocin (OT), dopamine, serotonin, and corticotropinreleasing factor (CRF) (Heisler et al, 2003; Lindblom et al, 2001; Lu et al, 2003; Sabatier et al, 2003a). OT, dopamine, and CRF enhance social bonding in animals (Lim et al, 2007; Liu and Wang, 2003; Young and Wang, 2004) and may play a similar role in human social cognition (Skuse et al, 2014;

*Correspondence: Dr ME Modi, Neuroscience Research Unit, Pfizer, 610 Main Street, Cambridge, MA 02139, USA, Tel: + I 617395068 I, E-mail: meera.modi@gmail.com

Received 28 August 2014; revised 22 January 2015; accepted 26 January 2015; accepted article preview online 5 February 2015
Walum et al, 2012). Recently, chronic neonatal activation of the MC4R was shown to enhance social behavior in the prairie vole (Microtus ochrogaster) during adulthood (Barrett et al, 2014). To determine the mechanism through which MC4R regulates the development of social behavior in that model, we investigated the interaction between the MC4R and OT during social bonding in the adult prairie vole.

Application of $\alpha$-melanocyte-stimulating hormone ( $\alpha$-MSH), an endogenous ligand of the MC4R, to hypothalamic brain slices containing the oxytocinergic paraventricular nucleus $(\mathrm{PVN})$ induces somatodendritic release of OT via the MC4R (Sabatier et al, 2003a). Somatodendritic release of $\mathrm{OT}$ acts in a autocrine manner to prime OT vesicle stores for activity-dependent release following physiological stimulation (Ludwig and Leng, 2006). In vivo, central $\alpha$-MSH administration induces $c$-fos expression in the OT containing neurons of the supraoptic nucleus (Sabatier et al, 2003b). MC4R activation also induces dopamine release in the nucleus accumbens (NAc) (Lindblom et al, 2001).

The interaction of MC4R with the OT system, though, is particularly intriguing, given the recent evidence that enhancing OT signaling may be of therapeutic value for 
improving social function in autism spectrum disorders (ASD) (Anagnostou et al, 2012; Andari et al, 2010; Gordon et al, 2013) and schizophrenia (Davis et al, 2014). Currently, the clinical efficacy of OT is limited by its poor penetration of the blood-brain barrier and short half-life in peripheral circulation (Guastella et al, 2013; Modi et al, 2014). However, the indirect enhancement of OT signaling through activation of the MC4R, a receptor for which brain-penetrant, selective agonists already exist, may circumvent the pharmacological limitations of OT (Modi and Young, 2012). MC4R agonism, therefore, may be a novel therapeutic strategy for treating social impairments in psychiatric disorders through the enhancement of endogenous OT signaling and other prosocial neurochemical systems (Young and Barrett, 2015).

As OT and dopamine interact acutely in the NAc to facilitate social bonding in the female prairie vole (Liu and Wang, 2003), we used this model to study the social effects of acute MC4R activation. Prairie voles are highly affiliative, socially monogamous rodents that form enduring social bonds between mates, known as pair bonds. Pair bonding can be assessed in the laboratory using a partner preference test (McGraw and Young, 2010). Partner preference formation has been well characterized in female prairie voles to be a consequence of more general cognitive processes, including social information processing and social reinforcement, that are modulated by both OT and dopamine (Liu and Wang, 2003; Ross and Young, 2009). Thus, the partner preference test in female prairie voles can be used to explore pharmacological interventions intended to improve social cognition in psychiatric disorders (Modi and Young, 2011).

Here we examined the effect of three clinically tested MC receptor agonists, the MC receptor peptide agonists, Melanotan I (MTI) and Melanotan II (MTII), and the small-molecule, selective MC4R agonist, Pf-446687, on partner preference formation in the prairie vole and the closely related, but non-monogamous, meadow vole (Microtus pennsylvanicus). We then explored whether the effect of $\mathrm{MC}$ agonists on partner preference is mediated through interaction with the OT system. To assess the potential contribution of OT to the behavioral effects of MC agonists in this paradigm, we examined (1) the neuroanatomical distribution of MC4R mRNA, the effect of MTII on (2) OT neuronal activation and (3) central OT release and (4) the effect of blocking OTR in the NAc on partner preference formation in female prairie voles.

\section{MATERIALS AND METHODS}

\section{Subjects}

Subjects were adult, sexually naive female and male prairie voles (60-120 days of age) and adult, sexually naive female and male meadow voles (60-150 days of age) from our colony maintained at Emory University. Animals were maintained at $22^{\circ} \mathrm{C}$ and on a $14: 10 \mathrm{~h}$ light/dark cycle with ad libitum access to food (high-fiber rabbit chow, Purina, St Louis, MO) and water. All procedures used in this study were conducted in accordance with the National Institutes of Health Guide for the Care and Use of Laboratory Animals and approved by the Institutional Animal Care and Use Committee of Emory University.

\section{Melanocortin Receptor Agonists}

Melanotan I (MTI) $\left[\mathrm{Nle}^{4}, \mathrm{D}-\mathrm{Phe}^{7}\right] \alpha-\mathrm{MSH}$ is a potent analog of $\alpha$-MSH with activity at the MC1, MC3, MC4, and MC5 receptors and good in vivo stability and biodistribution, but poor blood-brain barrier permeability (Hruby et al, 2011). Melanotan II (MTII), Ac-Nle-c[ $\left.\mathrm{Asp}^{5}, \mathrm{DPhe}^{7}, \mathrm{Lys}^{10}\right] \alpha$-MSH$\mathrm{NH} 2$, is of similar potency and promiscuity as MTI but enhanced in vivo stability $\left(\mathrm{T}^{1 / 2}: 1-2 \mathrm{~h}\right)$ and blood-brain barrier permeability because of its cyclic structure (Cai et al, 2005). Pf-446687 is a highly selective, brain-penetrant, nonpeptide MC4R agonist (Lansdell et al, 2010). As Pf-446687 is a small molecule there is the possibility that it will engage a different signaling pathway than the peptide agonists MTI and MTII (Breit et al, 2010). Therefore, as MTII is more likely to engage signaling pathways in a manner more similar to endogenous MCs, MTII was used in the mechanistic studies.

\section{Effects of MC Agonists on Partner Preference Formation}

Partner preference test. Subjects were cohabited with an opposite sex conspecific for $6 \mathrm{~h}$ with mating deterred by ovariectomy-induced nonreceptivity (Williams et al, 1992). This cohabitation paradigm is typically insufficient to induce partner preference in our laboratory. Subjects were then tested in a 3-h partner preference test in a three-chambered arena as previously described (Ahern et al, 2009a). The time spent in immobile social contact with each stimulus animal was used to determine partner preference. Partner preference data were analyzed with a mixed model ANOVA comparing time spent in immobile contact with the partner and the stranger, with stimulus animal being the within-subjects factor and treatment being the between-subjects factor. A significant main effect of stimulus animal was followed by a planned paired Student's $t$-test comparing time spent with partner and stranger for each treatment. Groups were considered to have a partner preference if they spent significantly more time in immobile contact with the partner than the stranger under a given treatment. Individual animals were considered to have formed a partner preference if they spent twice as much time in contact with the partner than with the stranger.

Peripheral administration of MTI and MTII in females. The effect of MTI and MTII on partner preference formation was first tested in female ( $N=10$ /group) prairie voles as the role of endogenous OT on partner preference formation has been most extensively studied in female prairie voles, including the neuroanatomical sites of action and interaction with the dopamine system (Ross and Young, 2009; Young et al, 2001, 2011; Young and Wang, 2004). Each drug was tested in a separate experiment on naive subjects. Subjects were injected intraperitoneally (i.p.) with MTI, MTII (1 and $10 \mathrm{mg} / \mathrm{kg}$ in $3.3 \mathrm{ml} / \mathrm{kg}, 0.9 \%$ saline; Alpha Diagnostics, San Antonio, TX), or vehicle ( $3.3 \mathrm{ml} / \mathrm{kg}, 0.9 \%$ saline $)$. Doses were scaled around those given to elicit behavioral responses in other rodent models (Dorr et al, 1988; Klenerova et al, 2008). The experimental animals were then cohabitated and tested in the partner preference test.

Peripheral administration of MTII in males. The effect of MTII on partner preference formation was then tested in adult male prairie voles to establish whether the effect on 
partner preference formation generalizes to both sexes. Although the role of the endogenous OT system on partner preference formation in males is not as well characterized, exogenous OT has been shown to facilitate partner preferences in male prairie voles (Cho et al, 1999). Subjects were injected i.p. with either MTII $(10 \mathrm{mg} / \mathrm{kg}$ in $3.3 \mathrm{ml} / \mathrm{kg}, 0.9 \%$ saline; $N=12)$ or saline $(3.3 \mathrm{ml} / \mathrm{kg}, 0.9 \%$ saline; $N=11)$. The experimental males were cohabitated for $6 \mathrm{~h}$ with an ovariectomized, nonreceptive female prairie vole and tested in the partner preference test.

Long-term effect of peripheral MTII administration in females. To determine whether the facilitation of the partner preference by MTII is enduring in the absence of direct pharmacological action, female prairie voles were injected with MTII $(10 \mathrm{mg} / \mathrm{kg})$ or saline $(n=9-11 /$ group $)$ and paired with a stimulus male for $6 \mathrm{~h}$. After cohabitation, the animals were singly housed for 7 days before the partner preference test without additional interaction. The half-life of MTII is $\sim 1-2 \mathrm{~h}$ (Ugwu et al, 1994).

Peripheral administration of MTII in meadow voles. Female meadow voles, which do not form OT-dependent partner preferences, were injected with MTII $(10 \mathrm{mg} / \mathrm{kg})$ or saline ( $n=9-11 /$ group) as described above to assess potential non-OT-dependent effects on social behavior. Females were cohabitated with sexually inexperienced males for $24 \mathrm{~h}$ and tested in the partner preference tested. The longer cohabitation periods reflected the reduced sociality of this species and were chosen to increase the likelihood of detecting druginduced partner preferences.

Peripheral administration of Pf-446687 in females. To identify the MC receptor through which MTII evokes social behavioral effects, adult female prairie voles ( $n=10$ /group) were injected i.p. with the selective MC4R small-molecule agonist, Pf- 446687 (1 or $10 \mathrm{mg} / \mathrm{kg}$; donated by Pfizer, New York, NY), dissolved in a volume of $0.1 \mathrm{ml}$ of $10 \%$ $\beta$-cyclodextrin in $0.9 \%$ sterile saline or vehicle alone. The females were then cohabitated with a stimulus male for $6 \mathrm{~h}$ and tested in the partner preference test.

\section{Localization of MC4R and OT mRNA}

MC4R in situ hybridization. Sense and antisense ${ }^{35}$ S-UTP-labeled RNA probes for MC4R mRNA were generated as previously described (Inoue et al, 2013). The template for the MC4R RNA probe was amplified from prairie vole brain cDNA and corresponds to nucleotides 5051425 of the mouse MC4R mRNA (NM_016977.4). Next, $20 \mu \mathrm{m}$ cryosections of prairie vole brains were hybridized with the probes and were then placed in BAS-5000 imaging plates (Fujifilm, Valhalla, NY) for 7 days. Images were visualized using the BAS-5000 Phosphoimager. Brightness and contrast were equally adjusted for all the images using Adobe Photoshop CS. Average of signal intensity in each brain region of two male brains was analyzed using MultiGauge software (Fujifilm) as photo-stimulated luminescence per square $\mathrm{mm}\left(\mathrm{PSL} / \mathrm{mm}^{2}\right)$ and graded as very high $\left(++++,>100 \mathrm{PSL} / \mathrm{mm}^{2}\right)$, high $(+++, 50-100 \mathrm{PSL} /$ $\left.\mathrm{mm}^{2}\right)$, intermediate $\left(++, 20-50 \mathrm{PSL} / \mathrm{mm}^{2}\right)$, and low $(+,<20$
$\mathrm{PSL} / \mathrm{mm}^{2}$ ). Intensity of the corpus callosum was used as a background and was subtracted from ROI intensity.

OT in situ hybridization. In situ hybridization for OT mRNA was performed as described previously (Ahern and Young, 2009b). Sections adjacent to the sections used for MC4R in situ hybridization were hybridized with the probe and were exposed to Kodak BioMax MR films for $3 \mathrm{~h}$. The slides were then dipped in Kodak NTB emulsion and exposed for $20 \mathrm{~h}$ before developing. Dark-field photomicrographs were taken using Nikon E800 microscope and a SPOT camera (Diagnostic Instruments, Sterling Heights, MI).

\section{Activation of OT-Positive Neurons after MTII Administration}

Females were injected with $10 \mathrm{mg} / \mathrm{kg}$ of MTII or saline $(n=6$ MTII; $n=5 \mathrm{Sal}$ ) and returned to their home cage. At $90 \mathrm{~min}$ after injection, subjects were anesthetized and perfused transcardially with $4 \%$ paraformaldehyde and the brains were sectioned coronally on a microtome at $35 \mu \mathrm{m}$. Sections underwent immunohistochemical processing to detect EGR1 (early growth response protein 1) and OT or arginine vasopressin (AVP) exactly as previously described (Barrett et al, 2014). Four to six bilateral sections from each subject containing the PVN were quantified at $\times 20$ magnification. The ratio of EGR1-positive OT (or AVP) to total OT- (or AVP-) positive cells was quantified in each section and then averaged to yield a total ratio for each animal. The number of EGR1-immunoreactive OT or AVP neurons resulting from each treatment were statistically compared using Student's $t$-test.

\section{In Vivo Microdialysis Sampling of OT Release}

Adult female prairie voles ( $n=9$ saline; $n=12$ MTII) were unilaterally implanted with microdialysis probes into the NAc as described previously (Ross et al, 2009). After 2 days of recovery, the animals were anesthetized with urethane $(1.6 \mathrm{~g} / \mathrm{kg}$ i.p.) and maintained under urethane for the duration of the experiment. Isotonic Ringer's solution was perfused through the probe at a flow rate of $3 \mu \mathrm{l} / \mathrm{min}$. After a 90-min equilibration period, samples were collected in $30 \mathrm{~min}$ bins. Two $30 \mathrm{~min}$ baseline samples were collected. The animals were then injected i.p. with either $10 \mathrm{mg} / \mathrm{kg}$ of MTII or isotonic saline. Three $30 \mathrm{~min}$ postdrug samples were then collected. The perfusion solution was then switched to a hypertonic Ringer's solution containing $1 \mathrm{M}$ $\mathrm{NaCl}$, as hypertonic saline is a well-established physiological stimulator of OT release in the brain (Neumann et al, 1993). Two final $30 \mathrm{~min}$ samples were collected under the hypertonic conditions to test the hypothesis that MTII drives local somatodendritic OT release that then potentiates axonal activity-dependent OT release in an autocrine manner. Animals whose probes did not remain patent for the duration of the sampling were removed from analysis.

OT concentration was determined using a sensitive radioimmunoassay (RIAgnosis, Munich, Germany) (Neumann et al, 1993; Neumann et al, 2013). Cross-reactivity of the polyclonal antiserum with AVP and other related peptides was $<0.7 \%$. Intra- and inter-assay coefficients of variation were in the $5-9 \%$ and $8-12 \%$ ranges, respectively. The level 
of detectability of the assay was in the $0.3-0.5 \mathrm{pg} /$ dialysate range.

Concentrations of OT in the dialysates were analyzed in a two-way mixed model ANOVA with treatment as a betweensubjects factor and phase as a within-subject factor. Before analysis, the samples with concentrations below the level of detection $(0.3 \mathrm{pg})$ were increased to $0.3 \mathrm{pg}$ to account for analytically induced low values, based on the level of detectability of the radioimmunoassay. Data were log transformed to achieve a normal distribution for analysis. The post hoc average values for each treatment phase (baseline, drug, and hypertonic saline) were generated and significant effects were compared between phases with a paired $t$-test. Data are depicted (Figure $4 a$ ) as a fold increase over baseline because of variability in peptide concentration in the dialysates generated by slight variability in the placement of probes relative to OT fibers in the NAc between animals.

\section{Coadministration of MTII and OT Receptor Antagonist}

Female, ovariectomized prairie voles were anesthetized and implanted with 26-gauge bilateral guide cannulas (Plastics One, Roanoke, VA) aimed at the NAc as described previously (Modi and Young, 2011). After 3 days of recovery, subjects were dosed in a $2 \times 2$ design, centrally receiving OT receptor antagonist (OTA) or vehicle and peripherally receiving MTII or vehicle. Site-specific microinjections were either $500 \mathrm{nl}$ of Ringer's Solution or $10 \mu \mathrm{g}$ of the OTA, d $\left(\mathrm{CH}_{2}\right)_{5}^{1}, \mathrm{Tyr}(\mathrm{Me})^{2}$, $\mathrm{Thr}^{4}, \mathrm{Orn}^{8}$, des-Gly- $\left.\mathrm{NH}_{2}^{9}\right)$-Vasotocin (H-2908 Bachem, Torrance, CA), dissolved in $500 \mathrm{nl}$ of Ringer's Solution (Fisher Scientific, Pittsburg, PA) per side ( $N=11-12 /$ treatment). Subjects were injected peripherally within 2 min of central injection with either MTII $(10 \mathrm{mg} / \mathrm{kg})$ or saline i.p, cohabitated for $6 \mathrm{~h}$ with a male and assessed for partner preference. Subjects with clogged or loose cannulae were excluded from analyses.

\section{RESULTS}

\section{Receptor Agonist Facilitates Partner Preferences}

Peripheral administration of MTI did not induce a partner preference at either 1 or $10 \mathrm{mg} / \mathrm{kg}$ (Figure 1a) in female prairie voles. There was no main effect of stimulus animal and no significant interaction, but there was an indiscriminate main effect of dose $\left(\mathrm{F}_{2,32}=4.569, p<0.05\right)$. In contrast, administration of MTII did increase partner preference formation in female prairie voles (Figure $1 \mathrm{~b}$ ). There was a main effect of stimulus animal $\left(\mathrm{F}_{1,24}=8.527, p<0.05\right)$; females receiving a $10 \mathrm{mg} / \mathrm{kg}$ dose of MTII, but not $1 \mathrm{mg} / \mathrm{kg}$ or saline, spent significantly more time in social contact with the partner than the stranger (partner $v s$ stranger time at $10 \mathrm{mg} / \mathrm{kg}, p<0.05)$. The ANOVA, however, failed to show a main effect of dose or significant interaction. MTII also facilitated partner preference formation in male prairie voles (Figure 1c). There was a significant main effect of stimulus animal $\left(\mathrm{F}_{1,21}=8.394, p<0.05\right)$. Males receiving MTII displayed a partner preference (partner vs stranger time at $10 \mathrm{mg} / \mathrm{kg}, p<0.05)$ not seen in saline-treated animals. The ANOVA, however, did not reveal a significant main effect of treatment or significant interaction.
To determine whether the partner preference that developed during MTII exposure was retained after the drug was cleared (MTII has a half-life of 1-2 h), we tested for partner preference 1 week after cohabitation and MTII administration (Ugwu et al, 1994). There was no main effect of stimulus animal, treatment, or interaction in the ANOVA. However as mating-induced partner preferences were previously shown to endure up to 2 weeks after mating and MTII resulted in a partner preference when tested immediately after cohabitation, we tested the a priori hypothesis that the MTII-treated animals would spend more time with the partner than the stranger using a planned paired Student's $t$-test. A single dose of MTII followed by a 6-h cohabitation period was sufficient to induce the expression of partner preference in the female prairie voles after a 7-day period of isolation (Figure 1d; partner $v s$ stranger time at $10 \mathrm{mg} / \mathrm{kg}, p=0.05$ ).

MTII failed, however, to facilitate partner preference formation in female meadow voles, which do not express OT receptors in the NAc and do not display OT-dependent partner preference formation. After $24 \mathrm{~h}$ cohabitation (Figure 1e), the ANOVA indicated no main effect of stimulus, dose, or significant interaction.

As MTII has activity at both the MC3 and MC4 receptors, we tested whether the highly selective MC4R agonist Pf-446687 mimicked the effects of MTII. Pf-446687 resulted in a significant main effect of stimulus animal $\left(F_{1,27}=\right.$ $10.183, p<0.05$, Figure $1 \mathrm{f})$, as animals receiving the $1 \mathrm{mg} / \mathrm{kg}$ dose $(p<0.05)$, but not the $10 \mathrm{mg} / \mathrm{kg}$ dose, spent significantly more time with the partner than the stranger. The ANOVA did not show a main effect of dose or interaction.

\section{MC4R mRNA Expression}

MC4R mRNA was distributed in several brain regions involved in the regulation of social behavior, including the prefrontal cortex, lateral septum, bed nucleus of the stria terminalis, medial amygdala, NAc, and PVN (Figure 2a, $2 \mathrm{~b}$ and Table 1). Intense signal was also observed in the forebrain in the nucleus of the lateral olfactory tract and medial amygdaloid nucleus and in the brainstem. Intermediate levels of MC4R mRNA were detected in the substantia nigra compact part, ventral tegmental area, dorsal raphe, and median raphe nucleus. Within the PVN, OT and MC4R mRNA showed considerable overlap, providing a potential mechanism for interactions of the MC and OT systems (Figure $2 \mathrm{c}$ and $\mathrm{d}$ ). No signal was detected in slices incubated with the corresponding sense probe. Semiquantitative analysis of the mRNA expression in representative regions including regions relevant to social attachment is shown in Table 1.

\section{MTII Activation of OT Neurons}

Activation of OT-positive neurons in the PVN by MTII was assessed via immunohistochemical detection of the immediate early gene product, EGR1. There was a significant increase in EGR1-immunoreactive OT neurons following MTII administration (Figure 3a; $p<0.05$ ). EGR1 was present in $14 \%$ of OT-positive cells following MTII treatment compared (Figure 3c) with $1 \%$ of OT-positive cells in saline-treated animals (Figure 3b). MTII induced EGR1 staining in $<1 \%$ of AVP-positive cells, a small but significant 
a

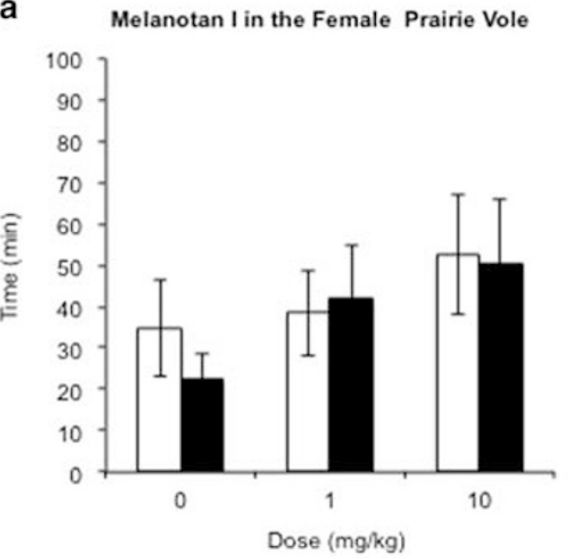

b

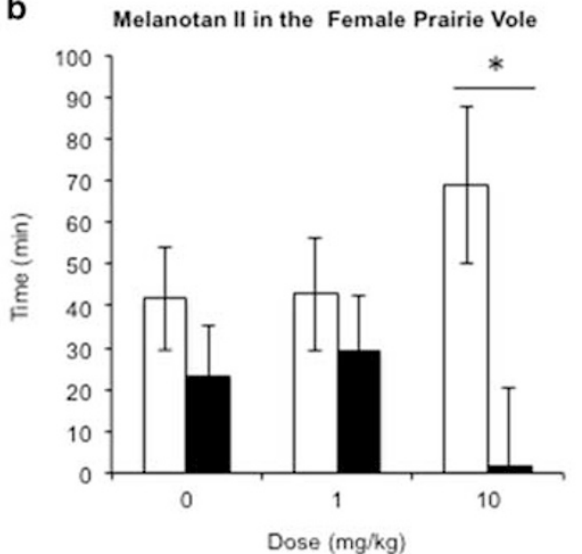

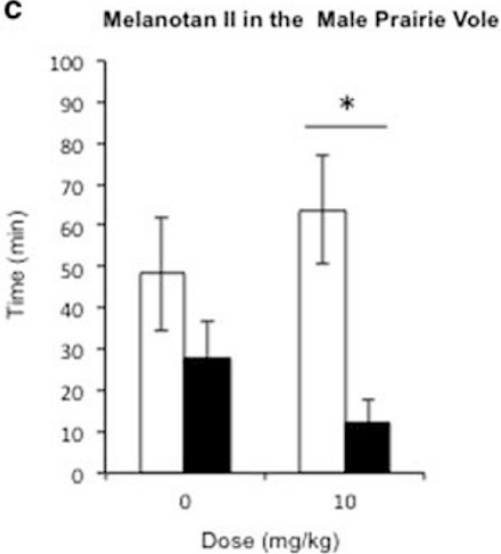
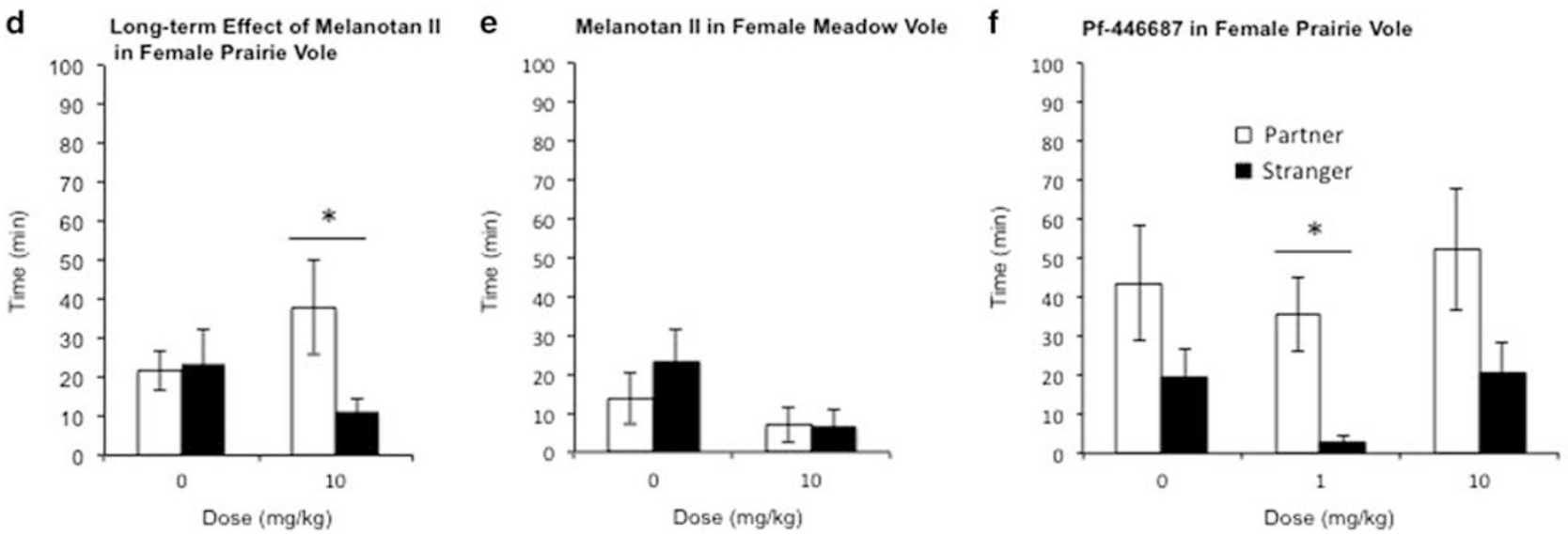

Figure I MTII facilitates immediate and long-term partner preference in prairie voles. (a) Female prairie voles given either a low or high dose of MTI failed to spend significantly more time with either stimulus animal and therefore did not form a 'partner preference'. (b) Female prairie voles receiving a high dose $(10 \mathrm{mg} / \mathrm{kg}$ ) of MTII (partner vs stranger $p<0.05$ ) spent significantly more time with the partner male vs the stranger male, indicative of a partner preference. (c) MTII $(10 \mathrm{mg} / \mathrm{kg}$ ) also induced partner preference formation in male prairie voles (partner vs stranger $p<0.05)$ under conditions in which vehicle-treated animals did not. (d) The effect of MTII (I0 mg/kg) is maintained in the female prairie voles after a 7-day period of separation. Comparison of time spent with the partner vs the stranger indicates a partner preference in MTII-treated animals (partner vs stranger $p<0.05$ ), with an average of three times more time spent with the partner than the stranger. (e) The administration of MTll had no effect on partner preference formation in meadow voles. There was no significant difference in the amount of time spent huddling with the partner or the stranger after $24 \mathrm{~h}$ of cohabitation. (f) Administration of Pf-446687 resulted in significant partner preference. Female prairie voles receiving a low dose $(\mathrm{I} \mathrm{mg} / \mathrm{kg}$ ) of MTII (partner vs stranger $p<0.05)$ spent significantly more time with the partner male vs the stranger male. The $10 \mathrm{mg} / \mathrm{kg}$ doses trended toward the formation of a preference but did not reach significance. *Indicates a statistically significant partner preference $(p<0.05)$.

increase over $0 \%$ activation in the saline-treated animals $(p<0.05)$.

\section{MTII Potentiates OT Release in the NAc}

We then used in vivo microdialysis to determine whether the activation of OT-positive neurons by MTII was sufficient to stimulate or potentiate OT release in the NAc. Peripheral MTII alone did not increase OT concentrations in the microdialysate samples from the NAc. However, compared with vehicle control, MTII results in a significantly greater OT release following hypertonic osmotic challenge, a potent stimulus for terminal OT release (Figure 4a). Comparison of raw OT concentrations using a two-way mixed model ANOVA (sample phase $\times$ treatment) revealed a significant difference in OT levels across sample phase $\left(\mathrm{F}_{6,114}=16.25\right.$, $p<0.05)$, reflecting the significant increase in OT concentrations stimulated by hypertonic saline administration.
There was no significant interaction between treatment and sample phase $\left(\mathrm{F}_{6}, 114=0.91, p>0.05\right)$. However, the MTII-treated animals had significantly elevated OT in the NAc microdialysates following hypertonic saline (in an average of the two samples) compared with baseline condition (in an average of the two samples) as demonstrated in a post hoc paired Student's $t$-test $(p<0.05)$. Animals receiving the control treatment showed no significant difference in OT levels between averaged hypertonic saline samples and baseline samples. These results are consistent with the potentiation of activity-dependent OT release resulting from local somatodendritic OT release within the hypothalamus.

\section{MTII-Induced Partner Preference Requires OTR Signaling in the NAc}

To determine whether the MTII-induced partner preference involved OTR signaling in the NAc, MTII was 


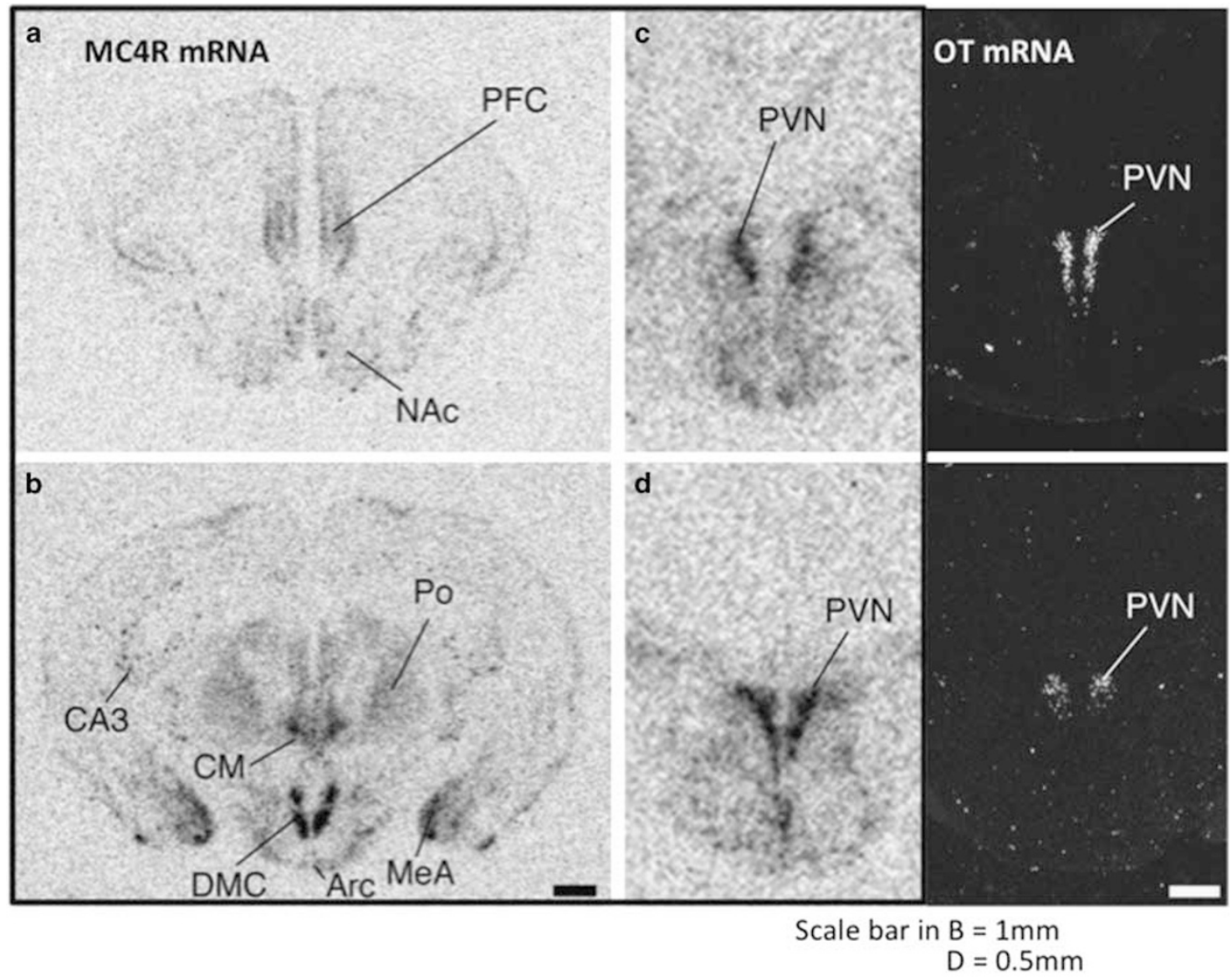

Figure 2 MC4R mRNA is present in the PVN of the prairie vole brain. $(a, b)$ MC4R mRNA was detected via in situ hybridization in numerous regions of the prairie vole brain involved the regulation of social behavior, including: the medial amygdala (MeA), nucleus accumbens ( $\mathrm{NaC}$ ), prefrontal cortex (PFC), CA3, the dorsal medial (DMC) and arcuate (Arc) nuclei of the hypothalamus, and the posterior (Po) and central medial (CM) thalamic nuclei. (c, d) Adjacent sections were used for MC4R (left) and for OT in situ hybridization (right.) Relevantly, MC4R mRNA was present in the paraventricular nucleus of the hypothalamus (PVN), one of the primary hypothalamic sites of OT synthesis of the prairie vole brain. The distribution of MC4R mRNA overlaps with the PVN regions expressing OT mRNA (dark field micrographs) in the caudal region (d) but not in the rostral region (c).

coadministered with an OTR antagonist infusion into the NAc (Figure $4 \mathrm{~b}$ ). There was a significant difference in the amount of time spent in immobile social contact with the partner $v s$ the stranger $\left(\mathrm{F}_{1,29}=7.190, p>0.05\right)$. Female prairie voles receiving control injections of both saline peripherally and Ringer's centrally did not show a group preference $(p>0.05)$, with 5 of the 10 animals showing a partner preference. Females receiving MTII peripherally and vehicle centrally did show a group preference $(p<0.05)$. In this group, 9 of the 12 animals displayed a partner preference (Figure 4b). Females that received both MTII peripherally and the OT receptor antagonist centrally did not show a partner preference $(p>0.05)$, with 4 of the 10 animals showing a partner preference.

\section{DISCUSSION}

\section{Effect of MC Agonists on the OT System and Partner Preference Formation}

Peripheral administration of brain penetrant MCR agonists enhances social cognition in the prairie vole as measured by the formation of partner preference. Both MTII and the
MC4R-selective Pf-446687 induced partner preferences in females after a 6-h cohabitation without mating. MTII also facilitated partner preference formation in male prairie voles, consistent with earlier observations that OT can facilitate partner preferences in males (Cho et al, 1999). Moreover, the effects of MTII on partner preference in females persisted 7 days after injection, well beyond the reported half-life of MTII (1-2 h; Ugwu et al, 1994). The effects of MTII on partner preference were inhibited by blockade of the OTR within the NAc, suggesting that the behavioral effects of MC4R agonists are mediated, at least in part, by central OTR signaling. MTII administration fails to induce a partner preference in the meadow vole, a species closely related to the prairie vole that lacks OTR in the NAc, further linking the prosocial efficacy of MTII to the OT system. Thus, MC receptor agonists could potentially be used to therapeutically enhance OT signaling for the treatment of social impairments in psychiatric disease.

Stimulation of MCR engages the central OT system. $\alpha$ MSH promotes somatodendritic, but not axon terminal release of OT in hypothalamic slices through MC4R signaling (Sabatier et al, 2003a). Somatodendritic release increases OT locally in the hypothalamus where it acts in an 
Table I Semiquantitative Levels of MC4R mRNA in Prairie Vole Brain Nuclei

\begin{tabular}{|c|c|c|c|c|}
\hline \multirow[t]{11}{*}{ Telencephalon } & Olfactory bulb & Glomerular layer, olfactory bulb & OB-GI & ++ \\
\hline & Cortex & & & \\
\hline & & Prelimbic cortex & PrL & + \\
\hline & & Dorsal peduncular cortex & DP & +++ \\
\hline & & Cingulate cortex & $\mathrm{Cg}$ & + \\
\hline & Nucleus accumbens & & & \\
\hline & & Accumbens nu, core & AcbC & + \\
\hline & Lateral septal nu, dorsal & & LSD & +++ \\
\hline & Amygdaloid nucleus & & & \\
\hline & & Medial amygdaloid nu & $\mathrm{MeA}$ & +++ \\
\hline & & Basolat amygdaloid nu & BLA & ++ \\
\hline \multirow[t]{8}{*}{ Diencephalon } & Medial preoptic nu & & MPO & ++++ \\
\hline & Paraventricular hypothalamic nu & & PVN & ++++ \\
\hline & Arcuate hypothalamic nu & & Arc & ++++ \\
\hline & Thalamic nuclei & & & \\
\hline & & Ventrolateral thalamic nu & $\mathrm{VL}$ & ++ \\
\hline & & Posterior thalamic nuclear group & Po & +++ \\
\hline & & Ventral posteromed thalamic nu & VPM & ++ \\
\hline & & Subparafascicular thalamic nu & SPF & ++++ \\
\hline \multirow[t]{2}{*}{ Mesencephalon } & Superficial gray, sup colliculus & & SuG & ++ \\
\hline & Periaqueductal gray & & PAG & ++ \\
\hline Rhombencephalon & Cerebellum Purkinje cell layer & & Pur & + \\
\hline
\end{tabular}

Intensity of MC4R mRNA signal in various brain nuclei is indicated as very high $(++++)$, high $(+++)$, intermediate $(++)$, or low $(+)$. Areas with no expression are not shown.

autocrine and paracrine manner to prime OT vesicle stores for activity-dependent release (Ludwig and Leng, 2006). We found that MC4R mRNA is colocalized with OT mRNA in the PVN and that peripheral infusion of MTII in our model robustly increases EGR1 immunoreactivity in a subset of PVN OT neurons. MTII alone had no effect on extracellular OT in microdialysate samples collected in the NAc, but it potentiated OT release in the NAc following a physiological stimulus (hypertonic saline) that causes terminal OT release (Neumann et al, 1993). Similarly, MTII may potentiate the endogenous OT release in the NAc induced by social interactions (Ross et al, 2009). We hypothesize that MTII stimulates somatodendritic release of OT from a subset of OT neurons in the PVN that increases local concentrations of OT in the PVN but not distal brain regions. This serves to prime the entire population of OT neurons through an autocrine or paracrine mechanism, leading to enhanced OT release from axon terminals in the NAc during social interactions with the partner, accelerating partner preference formation. If this hypothesis is correct, MC4R agonists would elevate OT concentration specifically in contexts that would evoke endogenous OT release, such as social interactions.

The efficacy of an MCR agonist in facilitating social behavior is dependent on the pharmacological profile of the compound, as MTII and Pf-446687, but not MTI, enhanced partner preference. Both MTI and MTII are agonists for $\mathrm{MC1}, 3$, 4, and 5R; however, because of its cyclic structure, MTII has enhanced in vivo stability and BBB permeability as compared with MTI (Hruby et al, 2011; Sawyer et al, 1980). Pf-446687 is highly selective for MC4R and is both brain penetrant and stable in vivo (Lansdell et al, 2010). Thus, the differential effects of MTII and Pf-446687 compared with MTI may be because of increased stability and/or access to 


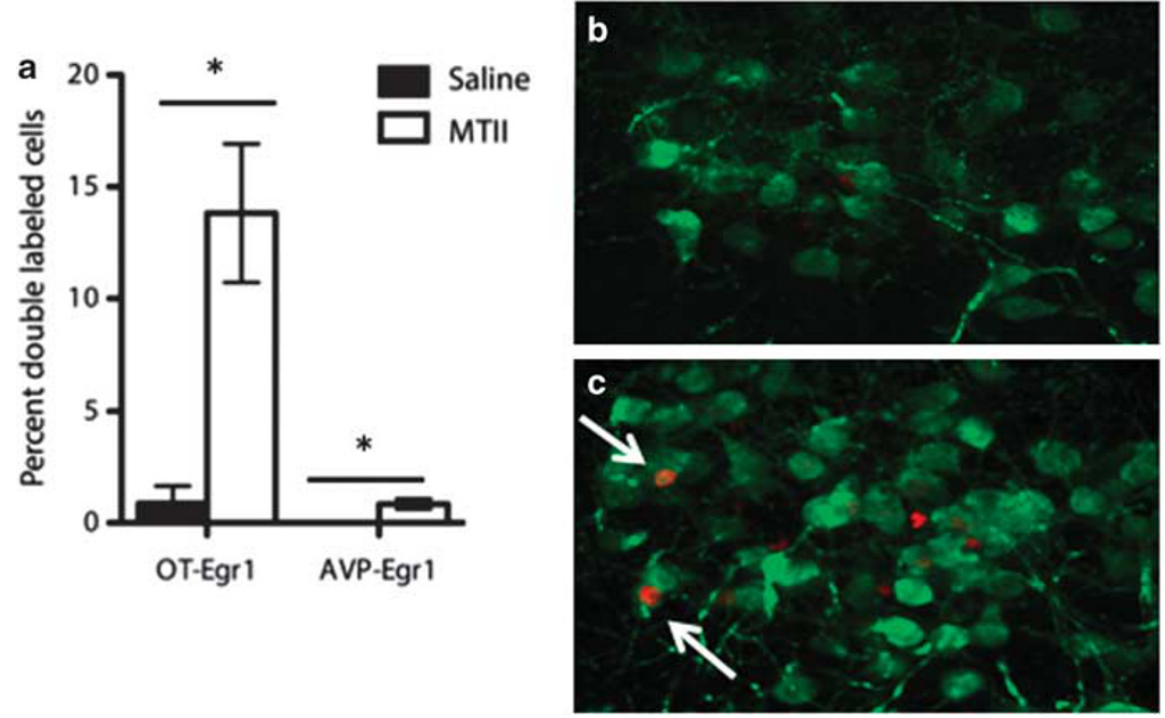

Figure 3 MTII activates OT-positive neurons in the paraventricular nucleus. (a) In the paraventricular nucleus of the hypothalamus, I3.8\% of OT-positive cells were activated by in vivo MTII administration, as indicated by EGRI expression, compared with $<1 \%$ of cells under control conditions ( $p<0.05$ ). Less than $1 \%$ of vasopressin-positive cell were activated by MTII administration. (b) OT-positive paraventricular cells after saline administration (green = OT, red $=E G R I$ ). (c) OT-positive cells after MTII administration. Arrows indicate colocalization of OT and EGRI. *Indicates a significant difference in the proportion of double-labeled neurons $(p<0.05)$.

a MTII Facilitates OT Release

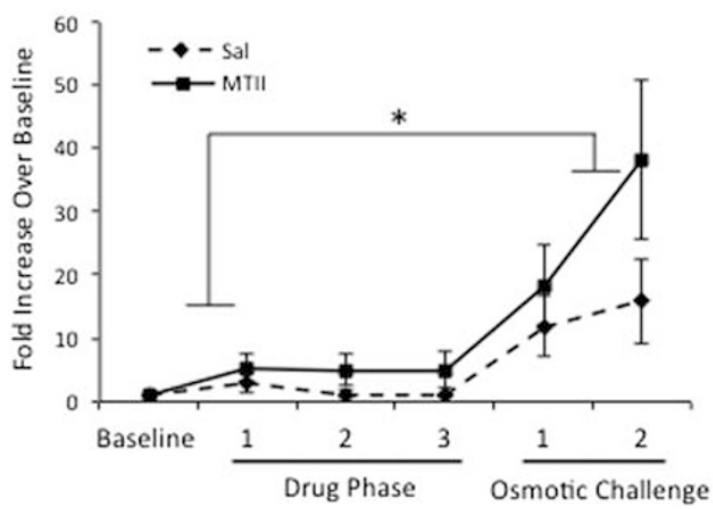

b

OTR-A Inhibits MTII Partner Preference Effect

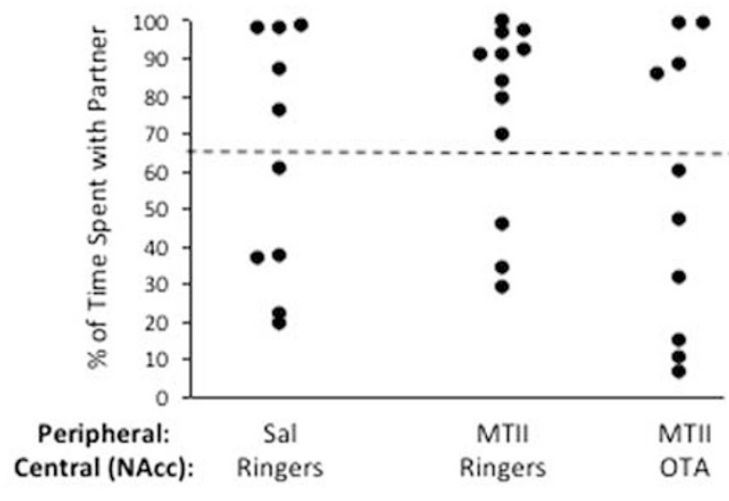

Figure 4 MTII interacts with the OT system. (a) Administration of MTII alone does not increase OT release relative to a vehicle control (Sal) in the drug phase. However, MTII does increase OT release in the NAc of female prairie voles in response to a hypertonic osmotic challenge, indicating a potentiating effect. The average OT levels after osmotic challenge are significantly higher than the average baseline OT levels in MTII but not saline-treated animals $(p<0.05)$. *Indicates a statistically significant increase in post hoc comparisons. (b) The facilitatory effect of MTII administration on partner preference was inhibited by administration of an OT receptor antagonist into the NA (OTA). Animals receiving the vehicle control (Sal+Ringers) showed no preference to spend time with the partner, whereas animals receiving MTII (MTII+Ringers) spent significantly more time with the partner than the stranger (partner vs stranger $p<0.05)$. OTA blocked the MTII-mediated preference for the partner. The dashed line is indicative of the 'twice as much time spent with the partner than the stranger' definition of binary partner preference.

central MC4Rs of these compounds. The lack of an effect of the non-BBB-penetrant MTI strongly suggests a central mode of action in this study. Central penetration could also account for the different dose response profiles between MTII and Pf-446687, as Pf-446687 has significantly greater BBB penetration compared with MTII (Smith and Modi, unpublished data). Thus, the $10 \mathrm{mg} / \mathrm{kg}$ dose of Pf- 446687 may be resulting in very high brain concentrations leading to off-target effects compared with $1 \mathrm{mg} / \mathrm{kg}$. In addition, smallmolecule MC agonists have been shown to have differential G-protein coupling and biased agonism, which may be dose dependent, potentially explaining why the higher dose of Pf446687 failed to facilitate partner preference (Breit et al, 2010).

Although our data support the hypothesis that the effects of MC4R agonists are mediated by a potentiation of OT 
release, they do not prove this or rule out other complementary mechanisms. MC4R mRNA is localized in several brain regions that regulate social and emotional behavior that could therefore affect partner preference formation, including the NAc, medial amygdala, and prefrontal cortex. Furthermore, MTII induces dopamine release through the activation of the ventral tegmental area (VTA) (Lindblom et al, 2001). Dopamine D2 receptor agonists infused into the NAc facilitate partner preference formation and blocking OTR in the NAc prevents this facilitation (Liu and Wang, 2003). Thus, MC4R agonists may also promote social bonding through activation of NAc dopamine circuits. Sitespecific infusion of MTII into the PVN, VTA, and other brain regions would be informative for further elucidating the mechanism of action for the behavioral results found in our study.

\section{Therapeutic Implications}

Partner preference formation in prairie voles represents a preclinical behavioral paradigm that may have face and construct validity for testing strategies to enhance social cognition in humans (Modi and Young, 2011). Partner preferences are thought to form as a consequence of the association of social stimuli with reward, a process mediated by OT and dopamine (Ross and Young, 2009). In humans, OT enhances attention to social cues, social information processing, and socially reinforced learning (Guastella et al, 2008; Hurlemann et al, 2010; Kemp and Guastella, 2010); however, the clinical potential of direct OT administration is limited by its poor pharmacokinetic profile (Guastella et al, 2013; Modi et al, 2014). Based on the efficacy of MC4R agonists at facilitating partner preferences in voles and the interaction of the receptor with the OT and dopamine system, MC4R may be a viable pharmacological target for enhancing social cognition, potentially in psychiatric disorders with impairments in social function, including ASD and schizophrenia.

Because of the role of the MC4R in sexual function, several agonists including those used in this study have been developed for clinical use, and therefore this target may offer a lower entry cost for its establishment as a therapeutic strategy. However, there are important caveats to MC4R agonist-based therapies because of its role in the regulation of appetite and sexual function (Chen et al, 2000; Wessells et al, 2000). Despite these limitations, our data suggest that clinical investigations of the effects of MC4R agonists on social cognition in psychiatric disorders such as ASD are warranted.

\section{FUNDING AND DISCLOSURE}

This research was funded by Autism Speaks Predoctoral Fellowship (to MEM), Autism Speaks no. 7745, and NIH Grants 1P50MH100023 and R01MH096983 (to LJY). Additional support was provided by OD P51OD011132 to YNPRC. LJY and MEM have applied for a patent for the use of MC4R agonists in the treatment of social cognitive deficits. MEM is currently employed by Pfizer, but was not so during the collection of the data presented. DGS was employed by Pfizer during the course of these experiments. Pf- 446687 was provided by Pfizer. KI, CEB, KAK, and RL declare no conflict of interest.

\section{ACKNOWLEDGMENTS}

We thank Sarah Osgood and Kari Fonseca for their bioanalytic work, Todd Ahern for his behavioral automation, Lorra Mathews for her role in animal husbandry, and Dr H. Gainer for generously providing monoclonal AVP antibodies.

\section{REFERENCES}

Ahern TH, Modi ME, Burkett JP, Young LJ (2009a). Evaluation of two automated metrics for analyzing partner preference tests. J Neurosci Methods 182: 180-188.

Ahern TH, Young LJ (2009b). The impact of early life family structure on adult social attachment, alloparental behavior, and the neuropeptide systems regulating affiliative behaviors in the monogamous prairie vole (microtus ochrogaster). Front Behav Neurosci 3: 17.

Anagnostou E, Soorya L, Chaplin W, Bartz J, Halpern D, Wasserman S et al (2012). Intranasal oxytocin versus placebo in the treatment of adults with autism spectrum disorders: a randomized controlled trial. Mol Autism 3: 16.

Andari E, Duhamel JR, Zalla T, Herbrecht E, Leboyer M, Sirigu A (2010). Promoting social behavior with oxytocin in highfunctioning autism spectrum disorders. Proc Natl Acad Sci USA 107: 4389-4394.

Argiolas A, Melis MR, Murgia S, Schioth HB (2000). ACTH- and alpha-MSH-induced grooming, stretching, yawning and penile erection in male rats: site of action in the brain and role of melanocortin receptors. Brain Res Bull 51: 425-431.

Barrett CE, Modi ME, Zhang BC, Walum H, Inoue K, Young LJ (2014a). Neonatal melanocortin receptor agonist treatment reduces play fighting and promotes adult attachment in prairie voles in a sex-dependent manner. Neuropharmacology 85: 357-366.

Breit A, Büch TRH, Boekhoff I, Solinski HJ, Damm E, Gudermann T (2010). Alternative G protein coupling and biased agonism: New insights into melanocortin-4 receptor signalling. Mol Cell Endocrinol 331: 232-240.

Cai M, Mayorov AV, Ying J, Stankova M, Trivedi D, Cabello C et al (2005). Design of novel melanotropin agonists and antagonists with high potency and selectivity for human melanocortin receptors. Peptides 26: 1481-1485.

Chen AS, Metzger JM, Trumbauer ME, Guan XM, Yu H, Frazier EG et al (2000). Role of the melanocortin-4 receptor in metabolic rate and food intake in mice. Transgenic Res 9: 145-154.

Cho MM, DeVries AC, Williams JR, Carter CS (1999). The effects of oxytocin and vasopressin on partner preferences in male and female prairie voles (Microtus ochrogaster). Behav Neurosci 113: 1071-1079.

Davis MC, Green MF, Lee J, Horan WP, Senturk D, Clarke AD et al (2014). Oxytocin-augmented social cognitive skills training in schizophrenia. Neuropsychopharmacology 39: 2070-2077.

Dorr RT, Dawson BV, al-Obeidi F, Hadley ME, Levine N, Hruby VJ (1988). Toxicologic studies of a superpotent alpha-melanotropin, [Nle4, D-Phe7]alpha-MSH. Invest New Drugs 6: 251-258.

Gordon I, Vander Wyk BC, Bennett RH, Cordeaux C, Lucas MV, Eilbott JA et al (2013). Oxytocin enhances brain function in children with autism. Proc Natl Acad Sci USA 110: 20953-20958.

Guastella AJ, Hickie IB, McGuinness MM, Otis M, Woods EA, Disinger HM et al (2013). Recommendations for the standardisation of oxytocin nasal administration and guidelines for its reporting in human research. Psychoneuroendocrinology 38: 612-625.

Guastella AJ, Mitchell PB, Mathews F (2008). Oxytocin enhances the encoding of positive social memories in humans. Biol Psychiatry 64: 256-258. 
Hadley ME (2005). Discovery that a melanocortin regulates sexual functions in male and female humans. Peptides 26: 1687-1689.

Heisler LK, Cowley MA, Kishi T, Tecott LH, Fan W, Low MJ et al (2003). Central serotonin and melanocortin pathways regulating energy homeostasis. Ann NY Acad Sci 994: 169-174.

Hruby VJ, Cai M, Cain J, Nyberg J, Trivedi D (2011). Design of novel melanocortin receptor ligands: multiple receptors, complex pharmacology, the challenge. Eur J Pharmacol 660: 88-93.

Hurlemann R, Patin A, Onur OA, Cohen MX, Baumgartner T, Metzler S et al (2010). Oxytocin enhances amygdala-dependent, socially reinforced learning and emotional empathy in humans. J Neurosci 30: 4999-5007.

Inoue K, Burkett JP, Young LJ (2013). Neuroanatomical distribution of mu-opioid receptor mRNA and binding in monogamous prairie voles (Microtus ochrogaster) and non-monogamous meadow voles (Microtus pennsylvanicus). Neuroscience 244: 122-133.

Kemp AH, Guastella AJ (2010). Oxytocin: prosocial behavior, social salience, or approach-related behavior? Biol Psychiatry 67: e33-e34; author reply e35.

Klenerova V, Krejci I, Sida P, Hlinak Z, Hynie S (2008). Effects of melanotan II, a melanocortin agonist, on grooming and exploration in rats after repeated restraint/immobilization. Neurosci Lett 432: 202-205.

Kokare DM, Dandekar MP, Singru PS, Gupta GL, Subhedar NK (2010). Involvement of alpha-MSH in the social isolation induced anxiety- and depression-like behaviors in rat. Neuropharmacology 58: $1009-1018$.

Lansdell MI, Hepworth D, Calabrese A, Brown AD, Blagg J, Burring DJ et al (2010). Discovery of a selective small-molecule melanocortin-4 receptor agonist with efficacy in a pilot study of sexual dysfunction in humans. J Med Chem 53: 3183-3197.

Lim MM, Liu Y, Ryabinin AE, Bai Y, Wang Z, Young LJ (2007). $\mathrm{CRF}$ receptors in the nucleus accumbens modulate partner preference in prairie voles. Horm Behav 51: 508-515.

Lindblom J, Opmane B, Mutulis F, Mutule I, Petrovska R, Klusa V et al (2001). The MC4 receptor mediates alpha-MSH induced release of nucleus accumbens dopamine. Neuroreport 12: $2155-2158$.

Liu Y, Wang ZX (2003). Nucleus accumbens oxytocin and dopamine interact to regulate pair bond formation in female prairie voles. Neuroscience 121: 537-544.

Lu XY, Barsh GS, Akil H, Watson SJ (2003). Interaction between alpha-melanocyte-stimulating hormone and corticotropin-releasing hormone in the regulation of feeding and hypothalamo-pituitaryadrenal responses. J Neurosci 23: 7863-7872.

Ludwig M, Leng G (2006). Dendritic peptide release and peptidedependent behaviours. Nat Rev Neurosci 7: 126-136.

McGraw LA, Young LJ (2010). The prairie vole: an emerging model organism for understanding the social brain. Trends Neurosci 33: 103-109.

Modi ME, Connor-Stroud F, Landgraf R, Young LJ, Parr LA (2014). Aerosolized oxytocin increases cerebrospinal fluid oxytocin in rhesus macaques. Psychoneuroendocrinology 45: 49-57.

Modi ME, Young LJ (2011). D-cycloserine facilitates socially reinforced learning in an animal model relevant to autism spectrum disorders. Biol Psychiatry 70: 298-304.

Modi ME, Young LJ (2012). The oxytocin system in drug discovery for autism: animal models and novel therapeutic strategies. Horm Behav 61: 340-350.

Neumann I, Ludwig M, Engelmann M, Pittman QJ, Landgraf R (1993). Simultaneous microdialysis in blood and brain: oxytocin and vasopressin release in response to central and peripheral osmotic stimulation and suckling in the rat. Neuroendocrinology 58: $637-645$

Neumann ID, Maloumby R, Beiderbeck DI, Lukas M, Landgraf R (2013). Increased brain and plasma oxytocin after nasal and peripheral administration in rats and mice. Psychoneuroendocrinology 38: 1985-1993.

Papadimitriou A, Priftis KN (2009). Regulation of the hypothalamicpituitary-adrenal axis. Neuroimmunomodulation 16: 265-271.

Ross HE, Cole CD, Smith Y, Neumann ID, Landgraf R, Murphy AZ et al (2009). Characterization of the oxytocin system regulating affiliative behavior in female prairie voles. Neuroscience 162: 892-903.

Ross HE, Young LJ (2009). Oxytocin and the neural mechanisms regulating social cognition and affiliative behavior. Front Neuroendocrinol 30: 534-547.

Sabatier N, Caquineau C, Dayanithi G, Bull P, Douglas AJ, Guan XM et al (2003a). Alpha-melanocyte-stimulating hormone stimulates oxytocin release from the dendrites of hypothalamic neurons while inhibiting oxytocin release from their terminals in the neurohypophysis. J Neurosci 23: 10351-10358.

Sabatier N, Caquineau C, Douglas AJ, Leng G (2003b). Oxytocin released from magnocellular dendrites: a potential modulator of alpha-melanocyte-stimulating hormone behavioral actions? Ann NY Acad Sci 994: 218-224.

Sawyer TK, Sanfilippo PJ, Hruby VJ, Engel MH, Heward CB, Burnett JB et al (1980). 4-Norleucine, 7-D-phenylalaninealpha-melanocyte-stimulating hormone: a highly potent alphamelanotropin with ultralong biological activity. Proc Natl Acad Sci USA 77: 5754-5758.

Seeley RJ, Drazen DL, Clegg DJ (2004). The critical role of the melanocortin system in the control of energy balance. Annu Rev Nutr 24: 133-149.

Shimazaki T, Chaki S (2005). Anxiolytic-like effect of a selective and non-peptidergic melanocortin 4 receptor antagonist, MCL0129, in a social interaction test. Pharmacol Biochem Behav 80: 395-400.

Skuse DH, Lori A, Cubells JF, Lee I, Conneely KN, Puura K et al (2014). Common polymorphism in the oxytocin receptor gene (OXTR) is associated with human social recognition skills. Proc Natl Acad Sci USA 111: 1987-1992.

Ugwu SO, Blanchard J, Nguyen LD, Hadley ME, Dorr RT (1994). A comparison of HPLC and bioassay methods for plasma melanotan-II (MT-II) determination: application to a pharmacokinetic study in rats. Biopharm Drug Dispos 15: 383-390.

Walum H, Lichtenstein P, Neiderhiser JM, Reiss D, Ganiban JM, Spotts EL et al (2012). Variation in the oxytocin receptor gene is associated with pair-bonding and social behavior. Biol Psychiatry 71: 419-426.

Wessells H, Levine N, Hadley ME, Dorr R, Hruby V (2000). Melanocortin receptor agonists, penile erection, and sexual motivation: human studies with Melanotan II. Int J Impot Res 12(Suppl 4): S74-S79.

Williams JR, Carter CS, Insel T (1992). Partner preference development in female prairie voles is facilitated by mating or the central infusion of oxytocin. Ann NY Acad Sci 652: 487-489.

Young KA, Gobrogge KL, Liu Y, Wang Z (2011). The neurobiology of pair bonding: insights from a socially monogamous rodent. Front Neuroendocrinol 32: 53-69.

Young LJ, Barrett CE (2015). Can oxytocin treat autism. Science 347: 825-826.

Young LJ, Lim MM, Gingrich B, Insel TR (2001). Cellular mechanisms of social attachment. Horm Behav 40: 133-138.

Young LJ, Wang Z (2004). The neurobiology of pair bonding. Nat Neurosci 7: 1048-1054. 